DOI: https://doi.org/10.33262/exploradordigital.v3i4.918

\title{
Propuesta de proyecto operativo de animación turística para el Club Temático de Jazz La Zorra y el Cuervo
}

\section{Proposal of tourist entertainment operating plan for La Zorra y el Cuervo Jazz. Thematic Club.}

Judith Sánchez Romero. ${ }^{1}$, Cindy León Abella. ${ }^{2}$ \& Amy Argibay Wood. ${ }^{3}$

\begin{abstract}
.
Tourist entertainment is one of the most significant matters inside the strategic view of any enterprise. The approaches of an entertainment \& leisure business must based on the healthy recreation of clients, the cultural integration and the well-planned entertainment. Thereby, this entertainment plan would become a success key factor and a differentiation feature of competitors. Nowadays, the lack of entertainment plans or the existence of plans created by repetitive and unoriginal activities are clear issues in Cuban entertainment \& leisure enterprises. For instance, La Zorra y el Cuervo is a theme club that has an artistic program only founded on daily performances of jazz groups well known for visitors. Thus, the main objective of this study is to design an Entertainment Operating Plan based on dynamic activities in relation to the jazz for La Zorra y el Cuervo Club". For achieving the main goal, it was used theoretical methods like the abstraction and integration, the analysis-synthesis and the inductive-deductive; and empirical methods such as the scientific observation, the interview and the survey to principal clients that all allow to determine the key activities in order to design the entertainment plan for the Jazz Club, and the plan pre-feasibility.
\end{abstract}

Keywords: Tourist entertainment; La Zorra y el Cuervo Jazz Club; Entertainment operating plan; Plan pre-feasibility.

\section{Resumen.}

La animación turística es considerada uno de los elementos importantes dentro de la concepción estratégica de cualquier instalación; las entidades de ocio y recreación juegan un papel esencial para el disfrute de los visitantes y la planificación de actividades de animación las convierte en un factor diferenciador con respecto a la competencia local existente. La ausencia de programas de

\footnotetext{
${ }^{1}$ Facultad de Turismo. Universidad de la Habana. Cuba. yudith.sanchez@ftur.uh.cu

2 Estudiantes de pregrado. Facultad de Turismo. Universidad de la Habana. Cuba,cyndi.abella@ftur.uh.cu

${ }^{3}$ Estudiantes de pregrado. Facultad de Turismo. Universidad de la Habana. Cuba, any.wood@ftur.uh.cu
} 
animación, o la existencia de estos, pero basados en actividades repetitivas y poco novedosas para el cliente, constituyen problemáticas evidentes en muchas entidades de ocio de Cuba. Tal es el caso del club de jazz La Zorra y El Cuervo, entidad que cuenta con una programación artística basada únicamente en las presentaciones diarias de grupos de jazz conocidos por los amantes del género. De ahí que, el propósito fundamental de este trabajo es diseñar un proyecto operativo de animación turística basado en actividades interactivas vinculadas al jazz para el club La Zorra y el Cuervo. Para dar respuesta a este objetivo se utilizaron tres procedimientos dentro de los métodos teóricos: abstracción e integración; inducción y deducción; análisis y síntesis; en los empíricos: el método de la encuesta como: la observación científica, la entrevista y el cuestionario dirigidas a clientes, permitieron determinar las actividades recreativas que conforman el proyecto operativo de animación de la entidad objeto de estudio, junto a un análisis de pre-factibilidad del mismo.

Palabras claves: Animación turística; Club La Zorra y el Curvo; Proyecto operativo de animación; Pre-factibilidad del proyecto.

\section{Introducción}

La animación turística, vista desde una óptica motriz que influye favorablemente en el ascenso turístico (o con efecto contrario en caso de estar mal formulada o implementada), juega un papel fundamental dentro de la concepción y planificación de cualquier centro receptor de turistas, encontrando especial importancia en las entidades de ocio, aquellas que basan su razón de ser en el entretenimiento y distracción de los visitantes que recibe, tales como hoteles, camping, parques temáticos, centros nocturnos, entre otros.

Es así que, la animación turística constituye un producto del ocio, que permite la generación de experiencias, el entretenimiento y el crecimiento personal, en cualquier ámbito en que se desarrolle dentro del marco turístico, es un fenómeno que combina dos elementos fundamentales, los recursos turísticos que logran atraer la atención del visitante y turista y los servicios que asisten a estos consumidores de ocio.

Según Fernández y Delgado (2009) el ocio no es sinónimo de tiempo libre sino toda aquella actividad humana que no genera valor en el sentido económico, realizada por los individuos en condiciones de libre elección y oportunidad relativas. En Cuba son todas aquellas instalaciones económicas cuyo fin es proveer servicios que satisfagan necesidades de arte y entretenimiento.

Es así como los llamados centros nocturnos, según la Resolución 35/2002 del Ministerio de Turismo de la República de Cuba se clasifican en: Discoteca, Sala de Fiesta, Club/ Club Temático y Cabaret.

La animación turística en centros nocturnos debe perseguir una tónica de espectacularidad y un interés participativo, con elevada integración humana y alto logro de objetivos didácticos para el cliente. Por tanto, la animación en estos centros también se pudiera considerar, según Paz (2018) la congregación de cinco elementos: productividad, con la participación del cliente; hacer del consumidor el principal objetivo de la animación; romper con los vicios de "vulgaridad; hacer de 
la actividad nocturna un espectáculo de calidad; y proyectar la imagen del animador como un mediador participativo con los clientes y los trabajadores.

Así mismo, todos los atractivos de un destino-país deben evolucionar de forma simultánea, para así garantizarle al turista una oferta integral y completa durante su estancia, asegurando su satisfacción y su posible regreso al lugar de acogida. De ahí que surjan entidades de ocio, como forma de diversificar la oferta turística, asumiendo programas de animación en correspondencia al Concepto del servicio que se brinda partiendo de las necesidades del entorno, y como principal función dentro de la planificación estratégica.

Es por ello que el POA, garantiza el desarrollo de los productos de animación y de los recursos humanos en conjunto, establece los objetivos que se deben perseguir, mediante medios de comunicación eficientes, que conduzcan hacia el rescate de los valores humanos y los recursos del patrimonio cultural y turístico.

Todo proyecto de animación debe fundamentarse sobre la propuesta bien trazada de alcanzar objetivos pedagógicos, como una estrategia de desarrollo para el cliente (De La Tejera, 2007).

Igualmente, el POA organiza, diseña y gestiona las acciones de animación en las instalaciones destinadas al ocio. Se orienta hacia la valoración de los productos turísticos naturales y antrópicos, y a las características y necesidades de los clientes en función de un mejor funcionamiento de la animación turística.

Sin embargo, la existencia de programas basados en actividades repetitivas y poco novedosos para el cliente, constituyen una problemática evidente en muchas entidades de ocio de la Isla. El resultado es, entonces, muchas oportunidades desaprovechadas para implementar una animación turística única, autóctona, capaz de conservar y transmitir los valores culturales de Cuba, tal y como se planteó en la concepción estratégica del Manual Técnico Metodológico para la Actividad de Animación Turística (1989).

Un ejemplo claro de la situación planteada, lo constituye el club temático La Zorra y el Cuervo, centrado en la música jazz. Actualmente, la entidad cuenta con una programación artística, la cual mantiene año tras años, basada únicamente en las presentaciones diarias de grupos de jazz conocidos por los amantes del género que constituyen los principales visitantes del lugar. Es de conocimiento por las autoras que la animación en este tipo de entidad presenta características peculiares, lo que no significa que sea inexistente, o que no se puedan desarrollar otras actividades interactivas que diversifique la programación y contribuya a un mejor posicionamiento del lugar en el destino.

De ahí, entonces, que el objetivo general de la presente investigación sea:

Diseñar un Proyecto Operativo de Animación, basado en actividades interactivas que diversifique la oferta, para el club de jazz La Zorra y el Cuervo. Lo novedoso de este trabajo radica que a partir 
de la metodología aplicada para el diseño del POA se pueden identificar potencialidades patrimoniales, culturales en función de la animación en correspondencia a públicos demandantes, permite mejorar la planificación recreativa de las entidades de ocio, provoca la visión de un producto interesante, renovado, flexible, sobre todo para la entidad objeto de estudio, para atraer a públicos potenciales a través de la diversificación de su programación sin perder su esencia.

\section{Marco metodológico}

Esta investigación dentro de los parámetros cualitativos se basa en un estudio descriptivo con carácter transformador, de manera que se interpreta el estado actual de la entidad y su programación artística, buscando desarrollar un cambio que, a través de la propuesta de un Proyecto Operativo de Animación, permita diversificar la programación artística de la instalación objeto de estudio y dar mérito verdadero al eslogan por el cual se conoce: La Casa del Jazz Cubano.

Por ello, para el diagnóstico se utilizaron dentro de los métodos teóricos dos de los procedimientos claves del pensamiento humano: análisis y síntesis; inducción y deducción; el método hipotéticodeductivo, en los métodos empíricos, el método de la encuesta: la observación científica, la entrevista, y el cuestionario dirigidas a diferentes públicos, y métodos estadísticos; junto a un análisis de pre-factibilidad, sustentado por la Metodología a utilizar para el diseño del Proyecto Operativo de Animación en el Club de Jazz La Zorra y el Cuervo.

La abstracción como procedimiento dentro de los métodos teóricos permite rebasar el nivel de lo concreto sensible y llegar a las cualidades esenciales del objeto de estudio, analizando exhaustivamente el fenómeno de la animación, se detecta que, a pesar de pequeñas incongruencias entre las metodologías analizadas, la mayoría de los procedimientos asumen una estructura similar, siendo fácil la opción de fusionarlos y asumir un único enfoque en el cual coinciden la mayoría de los autores. Sin embargo, una problemática encontrada es la referente a que la gran parte de las metodologías estudiadas se centran en el desarrollo de Proyectos Operativos para la Animación en hoteles, razón por la cual se determinó realizar una adaptación coherente de dichas metodologías para su aplicación en entidades de ocio y como resultado se decidió aplicar los siguientes pasos:

1. Datos generales de la entidad de ocio objeto de estudio.

2. Análisis de la animación turística.

- Valoración de los recursos de la entidad y del entorno.

- Identificación de potencialidades para la animación.

- Identificación de las potencialidades de los recursos humanos en función de la animación turística.

- Explotación de los recursos que identifican a la entidad de ocio.

1. Definición de los objetivos para el desarrollo de la animación en la entidad.

2. Definición de la clientela y sus segmentos por edades.

3. Estructuración de las actividades de animación por programas basados en los segmentos de la clientela. 
4. Evaluación de las necesidades materiales y de equipamiento con respecto al programa de actividades de animación que se proponen.

5. Análisis de la pre-factibilidad del proyecto.

Fue necesario, para el estudio de las características ociotípicas de los clientes demandantes, tomar como referencia el estudio realizado por la Escuela Superior de Administración y Dirección de Empresas (ESADE) de España en 2003 sobre los Ociotipos europeos, para poder determinar la estructura de las actividades y la definición de los programas dentro del POA.

Así mismo, se aplicó la técnica de gestión Segmentación por beneficios, para lo cual se efectúo una recopilación de información primaria. Se acudió al uso de Internet como principal fuente para la obtención de datos. Es así que, el acercamiento al cliente se constituyó a partir de una exhaustiva búsqueda de todos los comentarios referentes a la entidad objeto de estudio en la página web para viajeros TripAdvisor, y la también página web que posee el club, "Montuno Cubano" de origen francés.

La recopilación se centró en la revisión de más de mil comentarios efectuados en el año 2018, tanto en español como en inglés y francés, entre ambos medios promocionales. Se tuvieron en cuenta todos los usuarios que comentaron, accediendo a sus perfiles para obtener toda la información personal posible.

El estudio de los comentarios respondió a la acción de extraer los beneficios buscados que se encontraban implícitos en la valoración de los clientes; y por su parte, la revisión de los perfiles, a la inclusión de determinadas variables de caracterización. Además, como parte de las visitas a la instalación en horario operativo, se recogieron un total de 20 comentarios directos de los clientes, lo cual enriqueció la perspectiva y los resultados de la investigación.

Para la propuesta de beneficios esperados, se empleó la herramienta informática Microsoft Excel, donde se unificaron todos los datos recopilados y se dispusieron de forma lógica y organizada para su análisis y evaluación. Se listaron los beneficios esperados para la correspondiente segmentación. Se tomó como referencia las críticas tanto negativas como positivas, valoración de expectativas, experiencias vividas en el club e inclinación hacia temáticas específicas.

La información analizada y los beneficios planteados se presentaron frente a los principales directivos del centro nocturno, los cuales validaron el estudio y se procedió a la definición final del listado de beneficios.

Por último, para determinar la factibilidad cualitativa del POA para la entidad objeto de estudio, se decidió aplicar una Lista de Control o Criterio de Expertos, con el objetivo de obtener una valoración integral que justificara la magnitud de la inversión y que fuera compatible con los principales indicadores afectados. Para esto, se seleccionaron como expertos: al Productor Artístico y el Administrador General del Club objeto de estudio; una licenciada en turismo, una especialista económica, y una animadora turística, todos con más de 5 años de experiencia, los 
cuales estuvieron dispuestos a evaluar cualitativamente los indicadores propuestos, previamente determinados por las autoras del estudio.

\section{Resultados}

A partir de la información primaria obtenida sobre la situación actual de la programación artística en el Club de Jazz La Zorra y El Cuervo, tomando como base la metodología seleccionada y los resultados obtenidos con la aplicación de métodos, tanto teóricos como empíricos, se decidió formular el siguiente Proyecto Operativo de Animación para esta entidad de ocio.

\section{Datos generales de la entidad de ocio, objeto de estudio.}

El club temático La Zorra y el Cuervo, reconocida como la Casa del Jazz Cubano, es un espacio prestigioso y destacado del país, especializado en el género jazz, con más de 20 años de experiencia en su función actual. La entidad ostenta de una posición privilegiada en el Vedado capitalino, ubicado en el municipio de Plaza de la Revolución, en la avenida 23 entre las calles $\mathrm{N}$ y O. Abre sus puertas todos los días de 10:00 pm a 2:00 am. Cuenta con una capacidad máxima de 80 pax. Su cover varía en dependencia de las estrategias comerciales del Grupo Palmares, entre 10 a 15.00 CUC, con dos cocteles nacionales incluidos. Su programación incluye presentaciones en vivo de músicos jazzistas de renombre internacional, incluyendo a talentos jóvenes y aficionados.

\section{Análisis de la animación turística en la instalación.}

El estudio previo de los recursos existentes en la entidad y en el entorno cercano a la misma, permitió conocer cuáles elementos pueden ser aprovechados y/o explotados en aras de diversificar la programación de animación que contribuya a un mejor posicionamiento en el mercado, mantener la demanda turística con índices elevados, y garantizar la rentabilidad y la viabilidad comercial de la instalación objeto de estudio.

\section{Valoración de los recursos de la entidad y del entorno}

Recursos Patrimoniales: Dentro de la entidad se destaca un recurso fundamental que constituye patrimonio intangible del lugar y del país: el Jazz cubano.

Recursos Culturales: El Club de Jazz La Zorra y El Cuervo cuenta con recursos culturales que le otorgan un valor añadido a la entidad y contribuyen a conformar su Concepto de servicio. Entre ellos se pueden citar:

- Entrada al club simulando cabina telefónica inglesa

- Lugar subterráneo similar a los clubes de jazz norteamericanos ${ }^{4}$.

- Galería de importantes jazzistas cubanos y foráneos.

- Historia del Club: Data de antes del triunfo revolucionario en el año 1959. Su propia historia, y su éxito actual constituyen importantes impulsores del flujo turístico en la entidad.

\footnotetext{
${ }^{4}$ Dichos clubes, al igual que el género, tienen sus orígenes en Estados Unidos. La Zorra y El Cuervo existe como club nocturno desde antes del triunfo revolucionario.
} 
Otros recursos son: el mobiliario de madera (absorbe el sonido y permite que la música se proyecte y se escuche mejor ${ }^{5}$ ); punto de venta (servicio complementario); y oferta de bebidas y comidas ligeras.

Recursos del entorno:

- Agrupaciones de jazz cubano.

- Jóvenes artistas incursionando en el jazz.

- Generaciones de mujeres jazzistas.

- Celebridades del jazz internacional.

- Festival Internacional Jazz Plaza. ${ }^{6}$

\section{Identificación de potencialidades para la animación.}

- Esta entidad es reconocida actualmente por su propia demanda turística y por la concepción estratégica del lugar por el género musical que difunde.

- Cuantiosos eventos de jazz y recursos en el entorno relacionados con la temática.

- El diseño interior del lugar, unido a la representación escenográfica lograda, similar a los clubes de jazz norteamericanos.

- El formato de la programación artística actual se elabora y coordina con carácter mensual; y facilita la promoción del club, economizando los costos.

- La instalación cuenta con pocos trabajadores. Sin embargo, se integra por un equipo de trabajo multidisciplinario dispuesto a colaborar en las actividades de animación.

- Luego del análisis de la competencia del Club de Jazz La Zorra y El Cuervo, se detectó que la entidad, a pesar de que posee dos competidores importantes (Jazz Café y Café Miramar), resulta el Club de Jazz preferido por los clientes. Se pudo constatar que en ninguna de estas tres entidades existe un Proyecto Operativo de Animación, debido a la idea errónea de que el jazz no requiere ningún tipo de animación adicional.

\section{Identificación de las potencialidades de los recursos humanos en función de la animación turística.}

La entidad cuenta con una plantilla laboral ajustada a su concepción estratégica, limitada a una sola brigada de trabajo, donde se alternan los descansos consecutivamente. De esta forma, los recursos humanos están conformados por un Productor Artístico, un sonidista, un Capitán de salón, el Administrador General, dos dependientes gastronómicos, una lonchera, dos cantineros y un trabajador de seguridad. Algunos de ellos, con potencialidades para ejecutar alguna acción de animación.

\footnotetext{
${ }^{5} \mathrm{Si}$ el mobiliario fuera de hierro o vidrio, el retumbar del mismo debido al volumen del sonido, impediría que el jazz se escuchara con la calidad requerida, lo cual afectaría el ambiente sentimental y melódico diseñado para un mejor disfrute del género musical.

${ }^{6}$ Es un evento musical que se realiza anualmente en La Habana y que convoca a los más importantes artistas del género a nivel mundial, sirviendo de plataforma de lanzamiento a los nuevos talentos de Cuba.
} 


\section{Explotación de los recursos que identifican a la entidad de ocio.}

Para definir la explotación de los recursos que identifican a la entidad de ocio objeto de estudio se asumieron cinco criterios principales: por su nombre (imagen nacional e internacional), por su ubicación o el entorno, por su historia, y por el aprovechamiento de la animación.

- Por su nombre (imagen nacional e internacional): La Zorra y El Cuervo es un Club de Jazz reconocido internacionalmente como la Casa del Jazz cubano.

- Por su ubicación y el entorno: Ubicación céntrica en el Vedado capitalino, rodeada de importantes hoteles, restaurantes, bares, discotecas, museos, galerías de arte, entre muchos otros atractivos.

- Por su historia: Fundado desde 1957, abre sus puertas como Club Nocturno solamente, por esa fecha, se impuso como moda de la descarga musical luego funcionó como un centro nocturno de temática abierta, hasta que después de un proceso de restauración, en 1997, la antigua compañía Carishow, perteneciente al Grupo Cubanacán, decidió reanimar el club, reorientándolo definitivamente hacia el Jazz. Su historia a lo largo de seis décadas con un diseño peculiar y defensora del jazz, le otorgan a la entidad un gran valor artístico y cultural, y un sitio de excelencia a nivel nacional e internacional.

- Por el aprovechamiento de la animación: El Club de Jazz La Zorra y el Cuervo no cuenta con un Proyecto Operativo de Animación. Actualmente posee una programación artística conformada por conciertos de agrupaciones de jazz, en su mayoría cubanas, distribuidas a lo largo del mes. Según su administrador: "este tipo de entidad no utiliza ningún tipo de animación, porque el cliente lo que busca es meramente la música jazz interpretada en vivo". No hay frase más errónea posible, y la mayor dificultad radica en un conocimiento absurdo y retrógrado sobre el alcance de la animación turística y su adaptación a los diferentes contextos.

\section{Definición de los objetivos para el desarrollo de la animación en la entidad.}

- Diversificar la oferta durante todo el año, al imponerse como el único club de jazz con servicio de animación turística, diferenciándose al resto de los competidores.

- Incrementar en un $15 \%$ el índice de satisfacción del cliente con respecto a la animación y programación artística del club.

- Aumentar la rentabilidad de la empresa en un 5\% por concepto de animación turística para el próximo año operativo.

\section{Definición de la clientela y sus segmentos por edades.}

Las entrevistas realizadas al Administrador René Miquelerena del Jazz Club, y al Especialista Comercial de Ventas Internacionales Miguel Ángel Martí de la Agencia de Viajes Paraíso; para definir el tipo de cliente que visita la instalación, sus características fundamentales y sus preferencias en el destino. Así mismo, la aplicación de la Metodología planteada por la ESADE, resultó los siguientes resultados: 
Tabla 1: Características de los principales segmentos que visitan el Club de Jazz.

\begin{tabular}{|c|c|c|c|}
\hline País & Rango de edad & Preferencias/ Motivaciones & Ocio tipos \\
\hline EUA & $\begin{array}{l}\text { De } 28 \text { a } 35 \text { años } \\
\text { (jóvenes adultos) } \\
\text { y de } 37 \text { a } 56 \text { años } \\
\text { (adultos). }\end{array}$ & $\begin{array}{l}\text { El Jazz, los programas en vivo, experiencias } \\
\text { musicales, la improvisación y la mezcla de } \\
\text { ritmos cubanos, reconocidos jazzistas, ambiente } \\
\text { propicio de relajación y entretenimiento, y } \\
\text { actividad nocturna e interacción social. }\end{array}$ & $\begin{array}{l}\text { Hedonista y } \\
\text { Socioactivo }\end{array}$ \\
\hline Italia & $\begin{array}{l}\text { De } 25 \text { a } 34 \text { años } \\
\text { (jóvenes adultos) } \\
\text { y de } 40 \text { a } 62 \text { años } \\
\text { (adultos). }\end{array}$ & $\begin{array}{l}\text { La historia del género Jazz, la cultura, sus } \\
\text { características y la riqueza de las presentaciones } \\
\text { artísticas cubanas. La improvisación, las figuras } \\
\text { reconocidas, los eventos de Jazz y su difusión. }\end{array}$ & E-inquieto \\
\hline Inglaterra & $\begin{array}{l}\text { De } 22 \text { a } 36 \text { años } \\
\text { (jóvenes adultos); } \\
\text { y de } 48 \text { a } 64 \text { años } \\
\text { (Minoría) }\end{array}$ & $\begin{array}{l}\text { Buscan conocer del género Jazz en Cuba, hallar } \\
\text { los ritmos cubanos junto al Jazz, asistir a eventos } \\
\text { culturales y el encuentro con figuras reconocidas } \\
\text { cubanas. }\end{array}$ & Socioactivo \\
\hline Rusia & $\begin{array}{l}\text { De } 25 \text { a } 44 \text { años } \\
\text { (jóvenes adultos). }\end{array}$ & $\begin{array}{l}\text { Relación social y música clásica. Conocer } \\
\text { personas, intercambiar experiencias, disfrutar } \\
\text { del Jazz, la historia del género, sus características } \\
\text { y la riqueza de las presentaciones artísticas } \\
\text { cubanas. }\end{array}$ & Socioactivo \\
\hline
\end{tabular}

Fuente: Elaboración propia.

Estructuración de las actividades de animación por programas basados en los segmentos de la clientela.

Segmentación por beneficios esperados.

Los resultados de la aplicación de dicha técnica permitieron detectar los beneficios que buscan o esperan recibir los segmentos de demanda, lo cual se genera a partir de su percepción y valoración de la oferta. Luego de aplicarse la metodología que respalda dicha técnica y de analizar 876 comentarios y una lista de 17 beneficios fundamentales, resultaron tres segmentos perfectamente definidos:
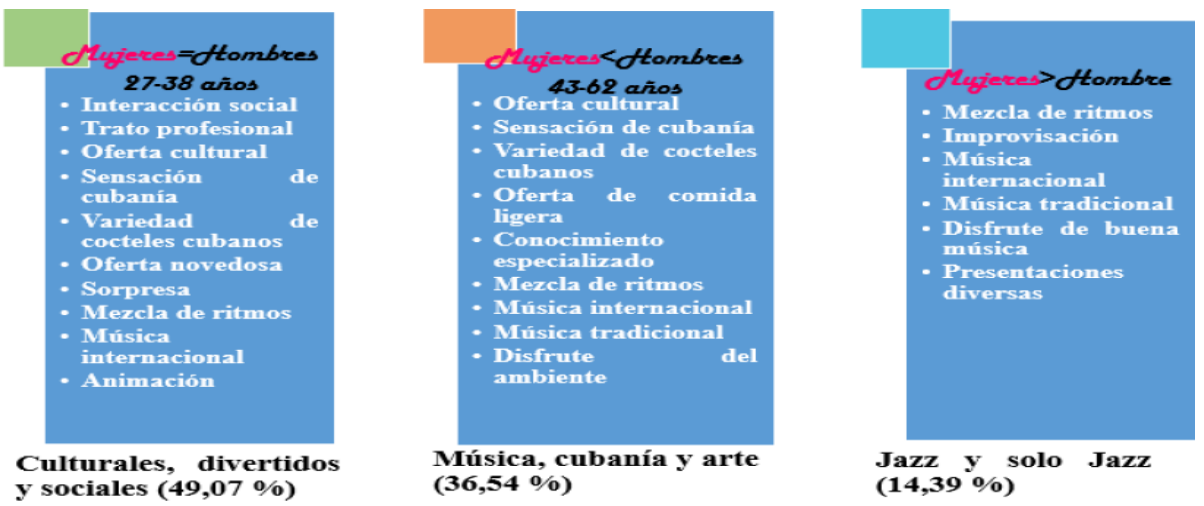

Figura 1: Grupos definidos mediante la segmentación por beneficios esperados.

Fuente: Elaboración propia. 


\section{Propuesta de actividades.}

- Tiempo de Homenajes. La actividad comenzará con una pequeña síntesis del músico a homenajear, sus aportes al Jazz, sus premios y legado artístico. Se proyectará en las pantallas del club, una de sus presentaciones como símbolo de admiración y respecto. Se efectuarán preguntas dinámicas al público acerca del jazzista en cuestión y finalmente, se desarrollará la presentación artística del músico contratado.

- Conociendo a los jazzistas cubanos. Consiste en un pequeño conversatorio inicial acerca del Jazz en Cuba y sus principales representantes. Se trasmitirán anécdotas y curiosidades referentes al tema. Luego tendrá lugar una degustación de tapas de la gastronomía cubana y finalmente, se desarrollará la presentación artística del músico contratado. Durante la presentación el público podrá valorar la interpretación y realizará una votación sobre el tema más gustado, podrán adquirir discos y se hará un juego de participación donde cada persona del público buscará debajo de su asiento para encontrar una invitación del músico a una de sus próximas presentaciones.

- Semana de "ElectroJazz". Constituirá un ciclo temático que dará a conocer de forma más explícita el ensamble entre el Jazz clásico, el Afro Jazz y la electroacústica, como parte de la contemporaneidad de la música jazzística en Cuba.

- Encuentro con “Mujeres Jazzistas”. El programa se realizará durante una semana al mes, conducido por las mujeres jazzistas del país e invitados internacionales que confirmen su participación en el encuentro. Las actividades se realizarán en dos secciones: en la mañana tendrán lugar conferencias y ponencias sobre las mujeres jazzistas en Cuba; la voz femenina en la difusión del género; mujeres percusionistas, pianistas y trompetistas; y el empleo del scat ${ }^{7}$ como discurso jazzístico de las féminas. Además, se propondrá una degustación de tapas criollas como almuerzo ligero. En la sección de la noche (horario habitual) se hará una pequeña reseña de las actividades diurnas y se contará con las presentaciones artísticas de las mujeres jazzistas cubanas. Al final de cada noche se obsequiará a cada fémina del público (incluyendo la artista invitada) una rosa como símbolo de amor y respeto.

- Presentación de “Jóvenes Jazzistas". Una semana al mes para promover a jóvenes jazzistas, quienes serán presentados por un jazzista consolidado del género y al finalizar la presentación facilitarán a los clientes entradas o invitaciones para sus próximos conciertos, así como promoverán sus discos.

- Noches Temáticas “Jazz Norteamericano". Estas noches comienzan con una breve introducción acerca de la historia del Jazz, se presentará al músico a homenajear en esa ocasión, sus logros y legado artístico se visualizará en las pantallas de la instalación una de sus presentaciones para recordar su estilo. Se efectuarán preguntas dinámicas al público acerca del jazzista en cuestión y finalmente, se desarrollará la presentación artística del

${ }^{7}$ En la música jazz, scat es un tipo de improvisación vocal, generalmente con palabras y sílabas sin sentido, convirtiendo la voz en un instrumento musical más. El scat da la posibilidad de cantar melodías y ritmos improvisados. 
músico invitado. El programa con algún juego de participación asociado a quiz musicales, donde los premiados podrán obtener souvenirs de la música Jazz, discos autografiados, invitaciones a conciertos o bebidas cubanas.

- Participación “Jo'Jazz" y Participación “Jazz Plaza". Se recomienda que el Club durante las ediciones de ambos eventos desarrolle un programa colateral para apoyar todas las actividades que se llevan a cabo durante las ediciones, convirtiéndose en anfitriona con propuestas novedosas, vinculadas a juegos participativos, concursos y sorpresas WAO.

Es preciso tener en cuenta un conjunto de acciones para la realización y materialización del proyecto, enfocadas a: la infraestructura, la ambientación, la señalética, la contratación artística, la restauración, la promoción y la distribución.

Propuesta de calendario para la programación de actividades.

Tabla 2: Calendario para los programas y actividades propuestas.

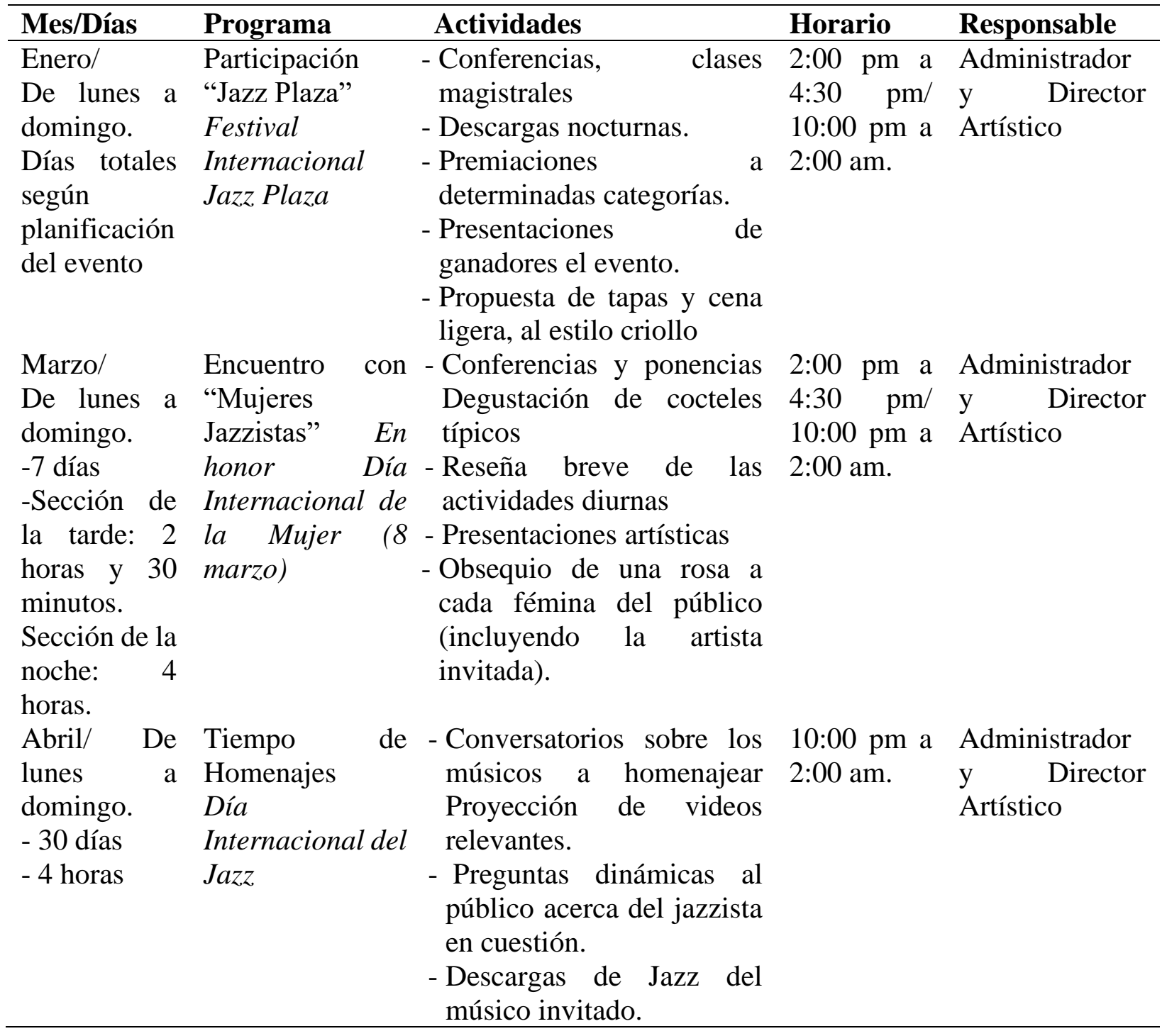




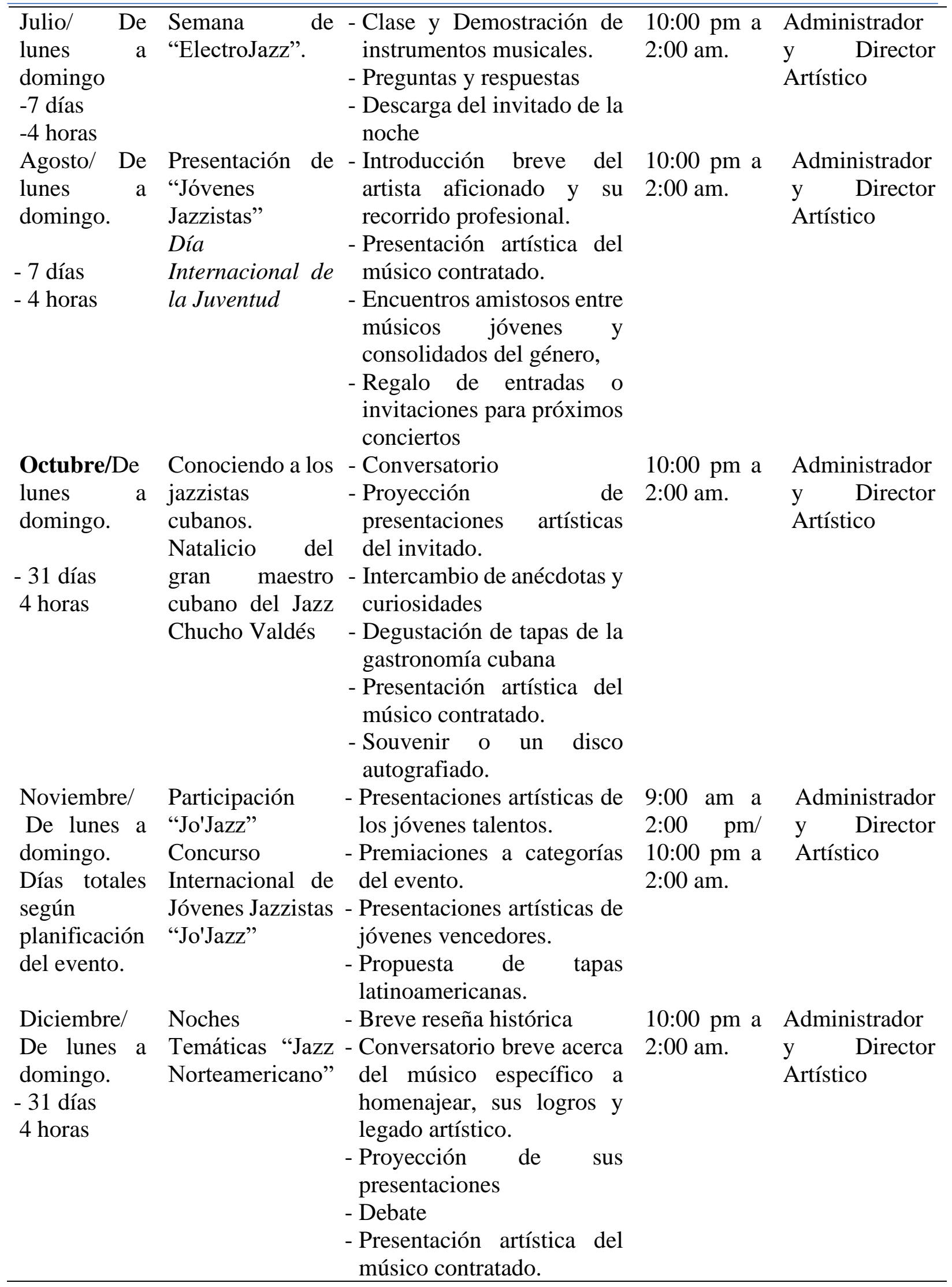


- Actividades de juegos de participación.

- Souvenirs o discos autografiados, invitaciones a conciertos $\mathrm{o}$ bebidas cubanas.

Fuente: Elaboración propia

\section{Evaluación de las necesidades materiales y de equipamiento con respecto al programa de actividades de animación que se propone.}

Para la consecución de los programas, la entidad cuenta con dos pantallas en buenas condiciones físicas, así como equipo de audio, y material audiovisual de músicos jazzitas célebres gracias a una cámara de video, propia de la instalación, con la cual se graban la mayoría de las presentaciones artísticas diarias programadas.

La instalación no cuenta con un especialista que tenga las competencias profesionales, para conducir las actividades de animación, por lo que se hace necesaria la contratación de un animador turístico. $^{8}$

\section{Análisis de la pre-factibilidad del proyecto.}

Factibilidad Cualitativa.

Los resultados a partir de la Lista de Control o Criterio de Expertos, Se decidió, entonces, tomar en cuenta cuatro criterios de factibilidad: operacional, comercial, financiero y estructural. A partir de los resultados obtenidos se determinó el Índice del Mérito Relativo para cada criterio evaluado y, posteriormente, el Índice del Mérito General, con el cual se obtuvo el por ciento de aceptación del proyecto, concluyendo que al ser superior al $80 \%$ (87,29\%) quedaba aceptada la ejecución del mismo por parte del grupo de expertos.

Factibilidad Cuantitativa.

Tabla 4. Costos asociados al sistema de actividades de los programas propuestos.

\begin{tabular}{lllllll}
\hline Actividad & \multicolumn{2}{c}{$\begin{array}{l}\text { Necesidades materiales y de } \\
\text { equipamiento }\end{array}$} & $\begin{array}{l}\text { Costo } \\
\text { Económico } \\
\text { Asociado }\end{array}$ & Duración & Costo Total \\
\hline $\begin{array}{l}\text { Tiempo } \\
\text { Homenaje }\end{array}$ & de & $\begin{array}{l}\text { Contratación de un artista } \\
\text { exponente del jazz }\end{array}$ & $\$ 120.00^{10}$ & 30 días & $\$ 3600.00$ \\
\hline
\end{tabular}

\footnotetext{
${ }^{8}$ Para el Proyecto Operativo se requiere de la contratación de un animador turístico con carácter fijo, o sea, que pase a formar parte de la plantilla laboral de la instalación. Esto significa que el animador turístico no tiene asociado un costo económico dentro del presupuesto asignado al proyecto operativo, sino que su salario se deduce al final del mes de forma similar al del resto de los trabajadores.

${ }^{9}$ Solamente se hará referencia a aquellas necesidades que lleven asociado un costo económico. El resto de elementos no se incluirán a fin de no afectar el análisis de la factibilidad económica del Proyecto Operativo.

${ }^{10}$ Según datos aportados por el Productor Artístico del Club de Jazz La Zorra y El Cuervo, la mayoría de las agrupaciones cobran un monto aproximado al que se indicó. Sin embargo, existen bandas que demandan un presupuesto mayor, dado su prestigio y notoriedad en el turismo nacional y foráneo.
} 


\begin{tabular}{|c|c|c|c|c|}
\hline Conociendo a los & Presentación $\quad$ artística $\quad$ del & $\$ 120.00$ & 30 días & $\$ 4880.00$ \\
\hline $\begin{array}{l}\text { jazzistas } \\
\text { cubanos }\end{array}$ & $\begin{array}{l}\text { músico contratado. Souvenir } \\
\text { relacionado con el Jazz o disco } \\
\text { autografiado (solo los viernes) }\end{array}$ & $320.00^{11}$ & 4 viernes & \\
\hline ElectroJazz & $\begin{array}{lcr}\begin{array}{l}\text { Contratación de un } \\
\text { exponente }\end{array} & \text { artista } \\
\text { electroacústica } & & \text { jazz }\end{array}$ & $\$ 120.00$ & 7 días & $\$ 840.00$ \\
\hline $\begin{array}{l}\text { Encuentro con } \\
\text { mujeres } \\
\text { jazzistas }\end{array}$ & $\begin{array}{l}\text { Presentaciones artísticas de las } \\
\text { mujeres jazzistas cubanas. } \\
\text { Flor como símbolo de amor y } \\
\text { respeto. }\end{array}$ & $\begin{array}{l}\$ 120.00 \\
20.00^{12}\end{array}$ & 7 días & $\$ 980.00$ \\
\hline Noches & Presentación artística del & 120.00 & 30 días & $\$ 4880.00$ \\
\hline $\begin{array}{l}\text { Temáticas de } \\
\text { Jazz } \\
\text { Norteamericano. }\end{array}$ & $\begin{array}{l}\text { músico contratado. Juegos } \\
\text { participativos: souvenirs de la } \\
\text { música Jazz, discos } \\
\text { autografiados, invitaciones a } \\
\text { conciertos o bebidas cubanas. }\end{array}$ & $320.00^{13}$ & $\begin{array}{l}\text { El suvenir } \\
\text { se dará } \\
\text { solamente } \\
\text { viernes (4) }\end{array}$ & \\
\hline TOTAL & & & 111 días & $\$ 15180.00$ \\
\hline
\end{tabular}

Fuente: Elaboración propia.

En primer lugar, se considera que las actividades propuestas cumplen su objetivo principal de diversificar la programación artística del Club de Jazz La Zorra y El Cuervo, pues ocupan un espacio temporal de 111 días, de los 365 que posee el año. Esto significa que durante 254 días la entidad puede mantener su programación artística habitual, y diversificarla con las actividades programadas para los 111 días restantes.

Para determinar si el proyecto es factible económicamente solo basta con seguir el razonamiento siguiente:

Tabla 5: Cálculo del presupuesto del programa de animación propuesto.

\begin{tabular}{lllllll}
\hline $\begin{array}{l}\text { Cover de la } \\
\text { instalación }\end{array}$ & $\begin{array}{l}\text { Demanda } \\
\text { media } \\
\text { diaria }\end{array}$ & $\begin{array}{l}\text { Ventas Diarias } \\
\text { (cover } \\
\text { demanda) }\end{array}$ & $\begin{array}{l}\text { Ventas } \\
\text { período } \\
\text { diarias x 111) }\end{array}$ & $\begin{array}{l}\text { del } \\
\text { POAtas }\end{array}$ & $\begin{array}{l}\text { Presupuesto } \\
\text { asignado al }\end{array}$ & Utilidad \\
\hline$\$ 15.00$ & 64 & $\$ 960.00$ & $\$ 106560.00$ & $\$ 15180.00$ & $\$ 91380.00$ \\
\hline
\end{tabular}

Fuente: Elaboración propia.

\footnotetext{
${ }^{11}$ Según se conoció en la entidad, el precio de los discos de exponentes del jazz en la instalación oscila alrededor de los 5.00 CUC. Asumiendo que la capacidad de la instalación es para 80 personas y que, generalmente, suele lograrse el $80 \%$ de esta capacidad (64 personas), se calcula un monto aproximado de $\$ 320.00$ por concepto de souvenirs o discos autografiados.

${ }^{12}$ Adquiriendo flores sencillas, del mercado nacional, se considera que asignando un costo de $0.25 \mathrm{CUC}$ por flor resulte suficiente. Si se tiene en cuenta la capacidad de la instalación (80 personas) y el hecho de que las flores restantes se pueden emplear en decorar el club (centros de mesa, por ejemplo) para así no perder el resto del presupuesto, se obtiene un monto total de 20.00CUC.

${ }^{13}$ Cualquiera de las alternativas seleccionadas para el juego de participación debe ajustarse al presupuesto planteado.
} 
Como se aprecia en la tabla anterior, el Proyecto Operativo de Animación propuesto es factible cuantitativamente porque la inversión que requiere representa solamente el $14.24 \%$ de las ventas logradas en el período indicado. Si a esto se añade el hecho de que no se ha incrementado el cover y que se deben adicionar las ventas derivadas de los 254 días resultantes del año, es evidente que invertir en este proyecto constituye una alternativa interesante, capaz de mantener la demanda y el prestigio alcanzado por el club, y de diferenciarlo, notablemente, con respecto a su competencia inmediata.

\section{Conclusiones}

- El Club de Jazz La Zorra y El Cuervo posee importantes recursos internos y del entorno que pueden ser aprovechados para llevar a cabo un proyecto operativo de animación que diversifique la oferta cultural.

- La metodología aplicada para diseñar la propuesta del proyecto operativo de animación, permitió identificar los recursos humanos, materiales, así como, las potencialidades patrimoniales y culturales de su entorno y de la entidad objeto de estudio, definiendo los objetivos alcanzables, para el desarrollo de la animación turística.

- El estudio de la demanda objetiva a través de la aplicación de la segmentación por beneficio y el estudio de los ociotipos, permitió reconocer las necesidades de ocio de los tres grandes grupos segmentados, siendo validados por los criterios de los expertos seleccionados, lo cual permitió definir los programas y sus actividades.

- El Proyecto Operativo de Animación propuesto es factible cuantitativamente porque la inversión que requiere representa solamente el $14.24 \%$ de las ventas logradas en el período indicado, lo que evidencia que invertir en este proyecto constituye una alternativa interesante, capaz de mantener la demanda y el prestigio alcanzado por el club, y de diferenciarlo, notablemente, con respecto a su competencia inmediata.

\section{Referencias Bibliográficas}

Abreu Hernández, P. P. (2004). Animación y Recreación Turística. No es lo mismo un animador turístico que un guía turístico. España. Obtenido de www.region.com

De La Tejera, E., \& Ulacia Oviedo, Z. (2007). La Animación en los Establecimientos Hoteleros. Gestión de Alojamientos. El área de animación. La Habana: Universidad de La Habana. Centro de Estudios Turísticos. Ciudad de la Habana.

Fernández Duménigo, L., \& Delgado Castro, A. (2009). La Gestión de Entidades de Ocio. La Habana: Universidad de la Habana. Centro de Estudios Turísticos. 
Chamba, L. (2015) Escenarios de Aprendizaje para la inclusión y cohesión social. Universidad de Loja. Ecuador. EDUTEC. Pág. 12. ISBN: 978-84-608-3627-8.

La Zorra y el Cuervo. (20 de diciembre de 2018). Obtenido de TripAdvisor: www.tripadvisor.com/sitiosdeinteréscuba/centros_nocturnos/la_zorra_y_el_cuervo

La Zorra y el Cuervo. (20 de diciembre de 2018). Obtenido de Montuno Cubano: www.montunocubano.com.

Matos Rodríguez, H. (2006). La Animación en Hoteles: Un Valor Añadido Infravalorado. EHT Varadero. CIDTUR INFORMA No. 69

Abreu Hernández, P. P. (2004). Animación y Recreación Turística. No es lo mismo un animador turístico que un guía turístico. España. Obtenido de www.region.com

De La Tejera, E., \& Ulacia Oviedo, Z. (2007). La Animación en los Establecimientos Hoteleros. Gestión de Alojamientos. El área de animación. La Habana: Universidad de La Habana. Centro de Estudios Turísticos. Ciudad de la Habana.

Fernández Duménigo, L., \& Delgado Castro, A. (2009). La Gestión de Entidades de Ocio. La Habana: Universidad de la Habana. Centro de Estudios Turísticos.

La Zorra y el Cuervo. (20 de diciembre de 2018). Obtenido de TripAdvisor: www.tripadvisor.com/sitiosdeinteréscuba/centros_nocturnos/la_zorra_y_el_cuervo

La Zorra y el Cuervo. (20 de diciembre de 2018). Obtenido de Montuno Cubano: www.montunocubano.com

Matos Rodríguez, H. (2006). La Animación en Hoteles: Un Valor Añadido Infravalorado. EHT Varadero. CIDTUR INFORMA No. 69.

Paz, A. (2015). Animación en Centros Nocturnos. Málaga: Universidad de Málaga.

\section{【 Ciencia}




\section{Para citar el artículo indexado.}

Sánchez Romero, J., León Abella, C., \& Argibay Wood, A. (2019). Propuesta de proyecto operativo de animación turística para el Club Temático de Jazz La Zorra y el Cuervo. Explorador Digital, 3(4), 96-112. https://doi.org/10.33262/exploradordigital.v3i4.918

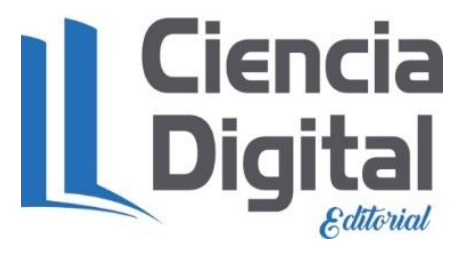

El artículo que se publica es de exclusiva responsabilidad de los autores y no necesariamente reflejan el pensamiento de la Revista Explorador Digital.

El articulo queda en propiedad de la revista y, por tanto, su publicación parcial y/o total en otro medio tiene que ser autorizado por el director o editor de la Revista Explorador Digital.

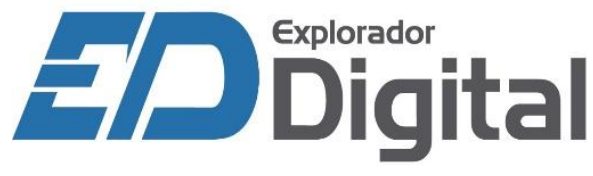

